\title{
Relative Kinetics of Precipitation and Adsorption of Arsenic(V) in Systems with Dissolved Iron(II)
}

\author{
JACKLIN JEKE NILLING AND ABHAS SINGH*
}

Dept. of Civil Eng., Indian Institute of Technology Kanpur,

U. P., India 208016 (*Correspondence: abhas@iitk.ac.in)

Geogenic pollution of aquifers with arsenic (As) is a serious environmental concern. Often, the mobilized As persists at saturation or slightly above saturation with respect to certain As-bearing solids, as was recently identified in a contaminated aquifer near Kanpur in the middle IndoGangetic basin. However, the kinetics of precipitation of these solids are poorly understood. The objective of this study was to measure the relative kinetics of $\mathrm{As}(\mathrm{V})$ precipitation and $\operatorname{As}(\mathrm{V})$ adsorption in conditions that favor formation of $\mathrm{Fe}(\mathrm{III})$ oxides. Initial batch studies with dissolved As and varying $\mathrm{Fe}(\mathrm{II})$ concentrations indicated $\mathrm{As}(\mathrm{V})$ uptake through three principal mechanisms: (a) formation of $\mathrm{Fe}(\mathrm{II})$-arsenates; (b) formation of $\mathrm{Fe}(\mathrm{III})$-arsenates; (c) adsorption on newly formed $\mathrm{Fe}$ (III) oxides. In order to quantify the relative kinetics of the above processes, subsequent flow-through studies were performed. Flow-cell reactors were preloaded with $3 \mu \mathrm{M}$ As(V) solution, buffered at $\mathrm{pH} 7.5$ using $\mathrm{NaHCO}_{3}$ at an ionic strength consistent with contaminated groundwater. Influent with variable dissolved $\mathrm{Fe}$ (II) concentrations, controlling the degree of initial saturation with respect Fe-As solids, were contacted with $\mathrm{As}(\mathrm{V})$ for fixed reactor residence times. Continuous time-dependent samples were collected and analysed for dissolved total As and total Fe using ICP-MS. Fe(II) and $\mathrm{pH}$ were also measured. Experiments were performed at different flow rates and matrices. The measured differential uptake of As and $\mathrm{Fe}$ relative to specific controls (closed and open symbols in Fig. 1) indicated precipitation of $\mathrm{Fe}$-arsenates amidst rapid formation of $\mathrm{Fe}$ (III) oxides. FE-SEM characterization on reactor solids at the end of the experiment confirmed As presence in these solids. Additional solid phase characterization results would be discussed to elucidate the phase(s) and As uptake mechanism(s) at specific conditions. Furthermore, results from reactive transport modelling of individual species would be presented to quantify reaction rates specific to the identified processes.

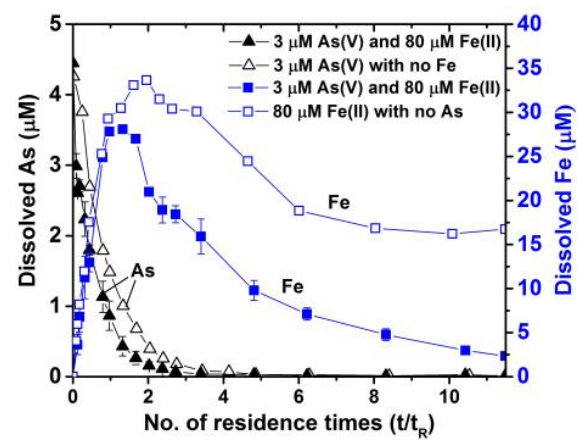

Figure 1: Timedependent variation in dissolved As and $\mathrm{Fe}$. 